\title{
Article \\ Functional Connectivity at Rest between the Human Medial Posterior Parietal Cortex and the Primary Motor Cortex Detected by Paired-Pulse Transcranial Magnetic Stimulation
}

\author{
Rossella Breveglieri ${ }^{1, *(\mathbb{D})}$, Sara Borgomaneri ${ }^{2,3}{ }^{\mathbb{D}}$, Matteo Filippini ${ }^{1}$, Marina De Vitis ${ }^{1}$, Alessia Tessari ${ }^{4}(\mathbb{D})$ \\ and Patrizia Fattori 1,5 \\ 1 Department of Biomedical and Neuromotor Sciences, University of Bologna, 40126 Bologna, Italy; \\ matteo.filippini7@unibo.it (M.F.); marina.devitis@unibo.it (M.D.V.); patrizia.fattori@unibo.it (P.F.) \\ 2 Center for Studies and Research in Cognitive Neuroscience, University of Bologna, 47521 Cesena, Italy; \\ sara.borgomaneri@unibo.it \\ 3 IRCCS Santa Lucia Foundation, 00179 Rome, Italy \\ 4 Department of Psychology "Renzo Canestrari", University of Bologna, 40127 Bologna, Italy; \\ alessia.tessari@unibo.it \\ 5 Alma Mater Research Institute for Human-Centered Artificial Intelligence (Alma Human AI), \\ University of Bologna, 40126 Bologna, Italy \\ * Correspondence: rossella.breveglieri@unibo.it; Tel.: +39-05-1209-1890; Fax: +39-05-1209-1737
}

Citation: Breveglieri, R.; Borgomaneri, S.; Filippini, M.; De Vitis, M.; Tessari, A.; Fattori, P. Functional Connectivity at Rest between the Human Medial Posterior Parietal Cortex and the Primary Motor Cortex Detected by Paired-Pulse Transcranial Magnetic Stimulation. Brain Sci. 2021, 11, 1357. https://doi.org/10.3390/

brainsci11101357

Academic Editor: Sandro Krieg

Received: 7 September 2021

Accepted: 11 October 2021

Published: 15 October 2021

Publisher's Note: MDPI stays neutral with regard to jurisdictional claims in published maps and institutional affiliations.

Copyright: (C) 2021 by the authors. Licensee MDPI, Basel, Switzerland. This article is an open access article distributed under the terms and conditions of the Creative Commons Attribution (CC BY) license (https:// creativecommons.org/licenses/by/ $4.0 /)$.

\begin{abstract}
The medial posterior parietal cortex (PPC) is involved in the complex processes of visuomotor integration. Its connections to the dorsal premotor cortex, which in turn is connected to the primary motor cortex (M1), complete the fronto-parietal network that supports important cognitive functions in the planning and execution of goal-oriented movements. In this study, we wanted to investigate the time-course of the functional connectivity at rest between the medial PPC and the M1 using dual-site transcranial magnetic stimulation in healthy humans. We stimulated the left M1 using a suprathreshold test stimulus to elicit motor-evoked potentials in the hand, and a subthreshold conditioning stimulus was applied over the left medial PPC at different inter-stimulus intervals (ISIs). The conditioning stimulus affected the M1 excitability depending on the ISI, with inhibition at longer ISIs (12 and $15 \mathrm{~ms}$ ). We suggest that these modulations may reflect the activation of different parieto-frontal pathways, with long latency inhibitions likely recruiting polisynaptic pathways, presumably through anterolateral PPC.
\end{abstract}

Keywords: medial posterior parietal cortex; functional connectivity; transcranial magnetic stimulation; paired pulse stimulation; parieto-M1 network

\section{Introduction}

Parieto-frontal networks are actively involved in monitoring arm movements such as reaching and grasping in monkeys [1-7] and in humans [8-16]. In the monkey brain, area V6A of the medial posterior parietal cortex contains reaching $[17,18]$ and grasping cells [19-22]. Given the knowledge of monkey V6A connections with the occipital, parietal, mesial and frontal cortices [23-25], area V6A may integrate sensory and motor-related input to estimate the limb state during arm movement, and participates in the exchange of information with the frontal cortex, specifically with the dorsal premotor cortex (PMd), which is in turn connected to the primary motor cortex (M1), and this is necessary to perform accurate interactions with objects in the peripersonal space $[2,26,27]$.

Area V6A also exists in humans (hV6A) [28] and is connected with the PMd via the superior longitudinal fasciculus [29,30]. Using resting-state fMRI, the same patterns of connections of hV6A were found in humans [8].

Given the fundamental importance of such parieto-frontal connections in orchestrating our movements, it appears to be crucial to investigate the time course of interactions 
between hV6A and M1 in healthy humans. Moreover, this knowledge represents a fundamental step for a deeper understanding of possible dysfunctions of such connections in pathological conditions. Interestingly, it has been reported that latency of the mutual information exchange is altered in neurological conditions such as Parkinson's disease and mirror dystonia [31,32].

As neuroanatomical studies in monkeys based on tracer injections cannot give information about the timing of connections, and fMRI studies rely on a correlational approach characterized by low temporal resolution, non-invasive brain stimulation techniques such as transcranial magnetic stimulation (TMS) appear better suited for disclosing the timecourse of hV6A-M1 causal interactions. Specifically, the dual-site TMS paired-pulse protocol (ppTMS) was successfully used for non-invasively mapping causal connectivity with high temporal resolution [11,12,33-40]. In the ppTMS protocol, a conditioning stimulus (CS) is administered over a target (e.g., parietal) area to activate direct or indirect pathways from the target site to M1. The CS is followed by a test stimulus (TS) administered over M1 to induce motor-evoked potentials (MEPs) in contralateral muscles. Both facilitation and inhibition may occur at the TS site (i.e., M1) depending on CS intensity and the interstimulus intervals (ISIs) between CS and TS [13,38].

The timing of the functional connections within the human parieto-frontal network was studied with ppTMS. Specifically, it has been found that when the CS administered in a region (superior parieto-occipital cortex, SPOC) that partially overlaps with the hV6A [10] precedes TS by $4 \mathrm{~ms}$, a MEP facilitation was observed during reach-to-grasp planning in the first dorsal interosseous (FDI) [11], whereas when CS precedes TS by $6 \mathrm{~ms}$, the same facilitation on a grasp-related muscle (abductor digiti minimi, ADM) was observed during whole-hand grasp planning [12].

The functional connectivity within the parieto-M1 network has been investigated not only during the planning of reaching and grasping movements, but also at rest. The seminal work of Koch demonstrated that a facilitation of MEPs can be obtained by a CS administered on the lateral posterior parietal cortex (PPC) preceding TS by 4, 6 and by $15 \mathrm{~ms}$ [13], depending on the hemisphere. However, when targeting the lateral PPC, different results have been obtained depending on the hemisphere and the site of the CS stimulation [41,42]. When considering other medial parietal sites, no modulations of MEPs evoked by the TS were observed; neither when the CS was delivered in area 5 [43] nor when it was administered in more posterior sites, such as SPOC [11]. Thus, different and inconsistent results have been obtained when investigating lateral PPC-M1 functional interactions at rest. Moreover, functional interactions between the medial PPC and the M1 are still largely unexplored. Specifically, ISIs longer than $10 \mathrm{~ms}$ have never been tested for medial PPC-M1 interactions; thus, the novelty of the present study is to provide new evidence about functional interactions involving medial PPC-M1 with longer latency, which can offer novel insights into clinical conditions associated with altered connectivity patterns.

Thus, we systematically studied the functional interactions between the medial PPC area $\mathrm{hV} 6 \mathrm{~A}$ and the M1 at rest using different ISIs ranging from $4 \mathrm{~ms}$ to $15 \mathrm{~ms}$. Our findings show a time-dependent modulation of the hV6A-M1 connectivity during a resting state, with long latency (12-15 ms) inhibition which likely reflects the recruitment of polysynaptic circuits.

\section{Materials and Methods}

\subsection{Participants}

Fourteen healthy volunteers (seven men, aged 19-34 years old) participated in this study. The number of participants is comparable with the sample size determined by a power analysis $((1-\beta)$ of 0.95 ; 2 -tailed $\alpha=0.05$; effect size $f=0.25$; number of measurements $=14$; correlation $=0.5$, analysis performed with $G^{*}$ Power software [44]).

All the participants were right-handed according to a standard handedness inventory [45], and had normal or corrected-to-normal visual acuity in both eyes. None of 
the participants had neurological, psychiatric, or other medical problems or any contraindication to TMS. Participants provided written informed consent, the procedures were approved by the Bioethical Committee at the University of Bologna (Prot. 57635, 11 March 2021), and were in accordance with the ethical standards of the Declaration of Helsinki (2013). No discomfort or adverse effects during TMS were reported or noticed.

\subsection{Localization of Brain Sites}

Before each experimental session, the positions of the coils were identified on each participant's scalp. The optimal scalp position for coil placement over the left M1 was defined on the participant's head wearing a bathing cap, as the point where stimulation evoked the largest MEPs from the contralateral first dorsal interosseous (FDI) muscle of the right hand (Figure 1). To identify area hV6A in the left hemisphere, we used frameless stereotaxic neuronavigation before each experimental session using the SofTaxic Navigator system (E.M.S. srl, Bologna, Italy) [46-48]. In the first stage, skull landmarks (nasion, inion, and 2 preauricular points) and 65 points providing a uniform representation of the scalp, were digitized by means of a Polaris Vicra Optical Tracking System (Northern Digital, Inc., Waterloo, ON, Canada). Coordinates in Talairach space were automatically estimated by the SofTaxic Navigator from an MRI-constructed stereotaxic template. This procedure has been proven to ensure a good localization accuracy, showing an error of roughly $5 \mathrm{~mm}$ in comparison to methods based on individual MRIs [48].
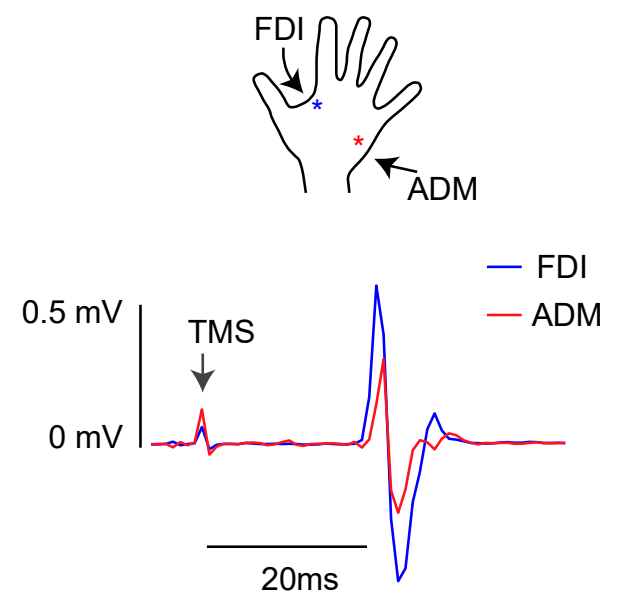

Figure 1. Typical EMG recording for FDI (blue trace) and ADM (red trace) muscle activity during rest. During the stimulation (TMS), artifacts on EMG trace are also shown.

The Talairach coordinates of hV6A we used were $\mathrm{x}=-10, \mathrm{y}=-78$, and $\mathrm{z}=40$ [49]. These coordinates are the same as those used in two previous TMS studies on hV6A [50,51], and are similar to those used for studying area SPOC [12,52], a region also investigated in imaging studies $[8,10,53]$ that likely includes hV6A [54]. Then, the neuronavigation system was used to estimate the projections of scalp sites on the brain surface. Mean coordinates \pm standard deviation corresponded to the $\mathrm{hV} 6 \mathrm{~A}(\mathrm{x}=-12.49 \pm 0.62 \mathrm{y}=-79.85 \pm 3.94$ $\mathrm{z}=38.92 \pm 3.97)$.

\subsection{Transcranial Magnetic Stimulation}

A dual-site, paired-pulse transcranial magnetic stimulation paradigm with two coils was used to test connectivity between the left PPC (hV6A) and the left M1. TMS pulses were administered via two T-shaped $50 \mathrm{~mm}$ butterfly coils, each of which was connected to a DuoMAG MP-Dual TMS System monophasic transcranial stimulator (DEYMED, Hronov, Czech Republic).

To set TMS intensity, the resting motor threshold (rMT) was estimated for all participants in a preliminary phase of the experiment using standard procedures [55]. MEPs 
induced by stimulation of the left motor cortex were recorded from the right first dorsal interosseous (FDI) and from the abductor digiti minimi (ADM) by means of a 2-channel DuoMAG MEP amplifier. Electromyography (EMG) signals were FIR-filtered and digitized at a sampling rate of $5 \mathrm{kHz}$. Pairs of disposable pre-gelled $\mathrm{Ag}-\mathrm{AgCl}$ surface electrodes were placed in a belly-tendon montage with a ground electrode on the wrist. The optimal scalp position for inducing MEPs from the right FDI was first localized, and the rMT was determined from that position. The rMT was defined as the minimal intensity of stimulator output that produced MEPs with an amplitude of at least $50 \mu \mathrm{V}$ in the FDI with a $50 \%$ probability [56]. The mean rMT across participants was $43.79 \%$, in line with other studies [57].

We administered TMS as the TS over M1 and the TS coupled with a preceding CS over hV6A with 6 ISIs $(4,6,8,10,12,15 \mathrm{~ms})$. We divided the stimulations into 3 blocks. In the first block, we tested the TS alone (s-pulse) or coupled with the CS (p-pulse) with 4 and $10 \mathrm{~ms}$ as ISIs; in the second block, the s-pulse and $p$-pulse were tested with ISIs of 6 and $8 \mathrm{~ms}$; in the third block, s-pulse and p-pulse were tested with 10 and $15 \mathrm{~ms}$ as ISIs. The order of the blocks, and the order of the pulses within each block, was randomized across participants. Each block consisted of 47 trials (7 TS trials, 20 CS-TS at each ISI) with a fixed inter-trial interval of $6 \mathrm{~s}$. A 3 min break was allowed between blocks. Participants sat on a comfortable chair in a darkened room and their head was kept stable using a head/chin rest. They were asked to keep both hands relaxed while testing, with the aim of obtaining a stable EMG signal. The intensity of TS was adjusted to elicit a motor-evoked potential (MEP) of $1 \mathrm{mV}$ peak to peak in the relaxed right FDI [13], and this corresponded to $120.32 \%$ of the rMT across participants. The intensity of the CS stimulus was set at $90 \%$ rMT [11-13]. Both coils were held tangential to the skull, with the M1 coil at $45^{\circ}$ and hV6A coil at $90^{\circ}$ from the mid-sagittal line to induce a posterior-anterior directed current in the underlying cortical tissue $[11,12]$.

\subsection{Electromyographic Recordings}

During each stimulation session, EMG was used to monitor muscle activity from FDI and from ADM. Surface electromyograms were recorded with $9 \mathrm{~mm}$ diameter, $\mathrm{Ag}-\mathrm{AgCl}$ surface-cup electrodes. EMG signals were recorded by means of a Digitimer D440-4 system (Digitimer, Welwyn Garden City, Hertfordshire, UK), amplified to $1000 \times$, band-passfiltered between $30 \mathrm{~Hz}$ and $1 \mathrm{kHz}$ with a sample rate of $5 \mathrm{KHz}$, recorded using a Micro1401 data acquisition interface controlled by Signal software v7 (Cambridge Electronic Design Ltd., Cambridge, UK), and stored on a computer for off-line analysis.

\subsection{Data Analysis}

The mean peak-to-peak MEP amplitude was computed for the s-pulse and $p$-pulse condition in each block. We checked for any trace showing EMG activity $100 \mathrm{~ms}$ prior to the TMS pulses and, in each condition, for any MEPs with amplitudes deviating from the mean by more than 2.5 standard deviations. No MEPs were discarded based on this analysis.

We averaged the MEP obtained in the s-pulse conditions of the 3 blocks because their MEPs were not statistically different between blocks (2-way ANOVA Muscle $x$ Block, all $p>0.46$ ). Thus, a two-way analysis of variance (ANOVA, with Greenhouse-Geisser correction for nonsphericity, Mauchly's test $p<0.05)$ with factors Muscle (2 levels, FDI and ADM), and TMS (7 levels, s-pulse, $p$-pulse4, $p$-pulse6, $p$-pulse8, $p$-pulse12, $p$-pulse15) was performed with the peak-to-peak MEP amplitude as the dependent variable. A post-hoc analysis was performed with the Newman-Keuls test in order to compare MEPs of the different conditions, and to correct for multiple comparisons. The significance level was set at 0.05 . 


\section{Results}

We recorded MEPs from FDI and ADM muscles at rest in different blocks, with the aim of studying the time course of the resting functional connectivity between $\mathrm{hV} 6 \mathrm{~A}$ and M1.

The functional connectivity between hV6A and M1 followed a specific time course, as demonstrated by the modulation of MEP amplitude by the CS. Specifically, MEP amplitude was influenced by TMS $\left(\mathrm{F}_{(6,78)}=8.11, p<0.001, \eta_{\mathrm{p}}{ }^{2}=0.38\right.$; Figure 2; mean values in Table 1; individual participants' data in Figure 3). This effect was driven by the reduction in MEP amplitude when ISI was longer than $10 \mathrm{~ms}$. This inhibition was significant at ISIs of $12 \mathrm{~ms}$ $(p<0.01)$ and $15 \mathrm{~ms}(p=0.02$, Figures 2 and 3$)$.

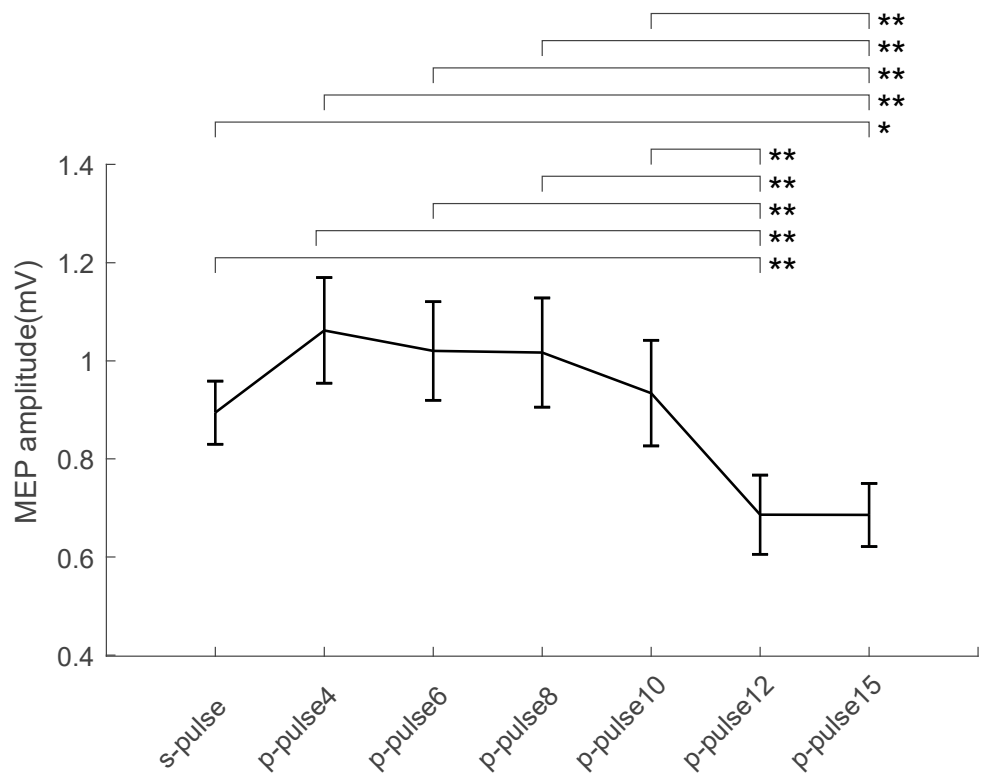

Figure 2. Physiological interactions between PPC and ipsilateral M1 at rest. Group-averaged $(n=14)$, muscle-averaged MEP amplitude ( $\mathrm{mV}$ ) for each ISI ( $p$-pulse) including TS alone (s-pulse) during rest. Lines above the bars represent significant differences (Newman-Keuls post-hoc comparisons, $\left.{ }^{*}=p<0.05,{ }^{* *}=p<0.01\right)$ between conditions. Error bars represent the standard error.

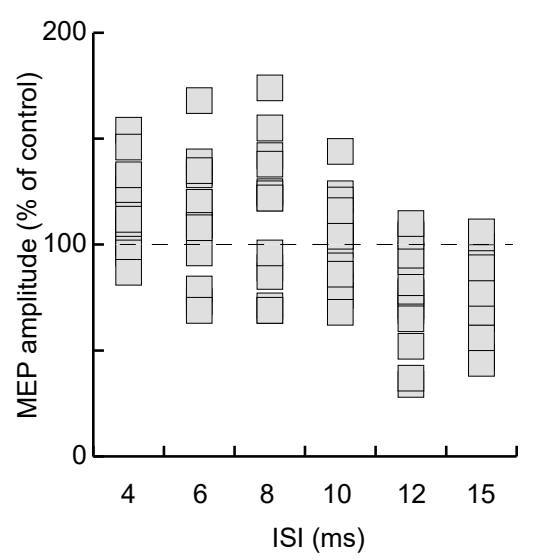

Figure 3. Individual participants' MEP amplitudes at the different ISIs. MEP amplitude is expressed as the percentage of the control condition (s-pulse). The dashed horizontal line represents 100\% (i.e., when the $p$-pulse condition equals the s-pulse condition). Each rectangle represents the mean MEP amplitude across trials in each participant. 
Table 1. Mean values and standard error of the MEP amplitude in the different TMS conditions.

\begin{tabular}{ccc}
\hline TMS & Mean & Standard Error \\
\hline s-pulse & 0.89 & 0.06 \\
\hline$p$-pulse4 & 1.06 & 0.10 \\
\hline$p$-pulse6 & 1.02 & 0.10 \\
\hline$p$-pulse8 & 1.02 & 0.11 \\
\hline$p$-pulse10 & 0.93 & 0.11 \\
\hline$p$-pulse12 & 0.69 & 0.08 \\
\hline$p$-pulse15 & 0.69 & 0.06 \\
\hline
\end{tabular}

MEP amplitude was also affected by the muscle $\left(\mathrm{F}_{(1,13)}=16.28, p<0.001, \eta_{\mathrm{p}}{ }^{2}=0.55\right)$, with MEP recorded from FDI larger than those recorded from $\operatorname{ADM}(p<0.001)$. On the contrary, the interaction of the factors muscle and TMS was not significant $\left(\mathrm{F}_{(6,78)}=2.93\right.$, $\left.p=0.06, \eta_{\mathrm{p}}^{2}=0.18\right)$, suggesting that the activation of the two muscles followed the same trend.

\section{Discussion}

In this work, we demonstrated that hV6A impacts ipsilateral M1 excitability at rest. This modulation was time-dependent, with significant inhibition for ISIs longer than 10 ms. These modulations imply that the two regions are functionally connected. Monkey and human studies have established that the connections between V6A and M1 are mainly indirect $[8,23,24]$. The shorter route from V6A to the frontal cortex is the connection with the $\mathrm{PMd}$, which in turn is connected to the M1 [8,23]. In humans, specifically, the connections between the superior parietal lobule and PMd lie within the first branch of the superior longitudinal fasciculus $[29,30,58]$. In contrast, anatomical evidence of a direct connection between the medial PPC and M1 is still lacking. We suggest that the inhibition we found at long ISIs could be the result of the activation of polysynaptic routes between $\mathrm{hV} 6 \mathrm{~A}$ and the frontal cortex. These longer pathways could involve either the connections between hV6A and PMd-M1, likely involving one or more interneurons within PMd and/or M1, or the direct connection of $\mathrm{hV} 6 \mathrm{~A}$ with the antero-lateral intraparietal regions (areas VIP, LIP and AIP) $[8,23]$, which in turn are connected directly to the M1 [59-61] or the spinal cord [42,62], or even more indirectly via the ventral premotor cortex [61]. This latter suggestion is supported by the inhibition found after conditioning the M1 with a CS in the antero-lateral intraparietal regions at ISIs between 2 and $6 \mathrm{~ms}$ [41].

\section{Comparisons with Other Studies about Parietal Resting Connectivity}

Resting state connectivity has extensively been tested with ppTMS in the human parieto-M1 network. When CS was administered over the lateral parietal cortex, different results were obtained according to the hemisphere tested [13,41], with inhibitory effects when CS preceded TS by $2-6 \mathrm{~ms}$ in different loci around the right intraparietal sulcus (IPS). Conversely, in the left hemisphere, inhibition followed the same time-course only when the CS was administered in the anterior IPS and an excitatory effect was observed when the CS was in the central and posterior IPS [41]. The inhibition for a $4 \mathrm{~ms}$ ISI in the left lateral anterior IPS was also confirmed by Vesia [11]. When CS was administered over the right posterior IPS, excitatory effects were observed at ISIs of 4 and $15 \mathrm{~ms}$, whereas in the left hemisphere, the same facilitation was found at ISIs of 4 and $6 \mathrm{~ms}$ [13]. Even if a strict comparison of the abovementioned results is difficult given the differences in the stimulation sites, the emerging frame about the left hemisphere is that after stimulation of anterolateral PPC, inhibitory effects over M1 are exerted, whereas excitatory effects are evident after the stimulation of posterolateral PPC [13,41]. Cattaneo and collaborators, on the contrary, found only inhibitory effects when CS was delivered on the lateral part of the superior parietal lobule [42]; however, this study was performed in anaesthetized brain 
tumor patients, so they may be not fully comparable with the results obtained in awake and healthy participants.

Differently from the abovementioned studies, our CS stimulation site was in the medial PPC, specifically in hV6A. Given the small extension of hV6A and the spread of the stimulation with a $50 \mathrm{~mm}$ coil, we cannot rule out the possibility that a spread of stimulation over neighboring areas occurred, namely, in the lateral portion of posterior Brodmann's area 7. However, the coil was centered on hV6A, and we delivered single pulses. The possible spread of the single pulse stimulation over neighboring areas would have only been in low intensity levels [63].

The anterior part of the medial PPC, specifically, the medial part of Brodmann's area 5, located rostrally to hV6A [54,64], did not have any effect on M1-evoked MEPs [43]. By administering CS more posteriorly, in the anterior part of Brodmann's area 7, Karabanov [65] found the facilitation of MEPs at 2 ms ISIs. Even more caudally, Vesia did not find any effect on M1 excitability [11] when CS was delivered on SPOC, a region that partially overlaps with our current stimulation site. This result corroborates what we found here, at least for ISIs from 4 to $10 \mathrm{~ms}$, which were tested in the current study and that of Vesia [11], where the observed effects did not reach the statistical threshold for significance.

The current study extends the results of Vesia by adding two longer ISIs in the experiments, and by demonstrating, for the first time, inhibitory effects of hV6A over M1 observed at longer ISIs.

\section{Conclusions}

Our experiments demonstrate the first evidence of a slow 12-15 ms inhibitory intrahemispheric cortico-cortical circuit between $\mathrm{hV} 6 \mathrm{~A}$ and M1. We suggest that the connectivity at rest of hV6A with the M1 may involve the antero-lateral intraparietal cortex, or interneurons within the premotor cortex and/or M1. How these connections can be recruited during reaching and grasping planning will be the object of future studies.

Author Contributions: Conceptualization, R.B., S.B.; Methodology, R.B., S.B.; Software, R.B., M.F., A.T.; Validation, A.T., P.F.; Formal Analysis, R.B., S.B., M.D.V.; Investigation, R.B., S.B.; WritingOriginal Draft Preparation, R.B.; Writing-Review and Editing, all authors; Funding Acquisition, P.F. All authors have read and agreed to the published version of the manuscript.

Funding: This work was supported by MAIA project, which has received funding from the European Union's Horizon 2020 research and innovation programme under grant agreement No 951910. This article reflects only the author's view and the Agency is not responsible for any use that may be made of the information it contains.

Institutional Review Board Statement: The procedures were approved by the Bioethical Committee at the University of Bologna (Prot. 57635, 11 March 2021) and were in accordance with the ethical standards of the Declaration of Helsinki.

Informed Consent Statement: Participants provided written informed consent.

Data Availability Statement: The data presented in this study are available on reasonable request from the corresponding author.

Acknowledgments: We wish to acknowledge Samane Maleki and Pietro P. Cesari for the considerable help in the lab setup, data analysis and collection.

Conflicts of Interest: The authors declare no conflict of interest.

\section{References}

1. Galletti, C.; Kutz, D.F.; Gamberini, M.; Breveglieri, R.; Fattori, P. Role of the medial parieto-occipital cortex in the control of reaching and grasping movements. Exp. Brain Res. 2003, 153, 158-170. [CrossRef] [PubMed]

2. Fattori, P.; Breveglieri, R.; Bosco, A.; Gamberini, M.; Galletti, C. Vision for Prehension in the Medial Parietal Cortex. Cereb. Cortex 2017, 27, 1149-1163. [CrossRef] [PubMed]

3. Janssen, P.; Scherberger, H. Visual Guidance in Control of Grasping. Annu. Rev. Neurosci. 2015, 38, 69-86. [CrossRef] [PubMed] 
4. Bonini, L.; Serventi, F.U.; Bruni, S.; Maranesi, M.; Bimbi, M.; Simone, L.; Rozzi, S.; Ferrari, P.F.; Fogassil, L. Selectivity for grip type and action goal in macaque inferior parietal and ventral premotor grasping neurons. J. Neurophysiol. 2012, 108, 1607-1619. [CrossRef] [PubMed]

5. Rizzolatti, G.; Matelli, M. Two different streams form the dorsal visual system: Anatomy and functions. Exp. Brain Res. 2003, 153, 146-157. [CrossRef] [PubMed]

6. Pesaran, B.; Nelson, M.J.; Andersen, R.A. Dorsal Premotor Neurons Encode the Relative Position of the Hand, Eye, and Goal during Reach Planning. Neuron 2006, 51, 125-134. [CrossRef] [PubMed]

7. Snyder, L.H.; Batista, A.P.; Andersen, R.A. Intention-related activity in the posterior parietal cortex: A review. Vis. Res. 2000, 40, 1433-1441. [CrossRef]

8. Tosoni, A.; Pitzalis, S.; Committeri, G.; Fattori, P.; Galletti, C.; Galati, G. Resting-state connectivity and functional specialization in human medial parieto-occipital cortex. Brain Struct. Funct. 2015, 220, 3307-3321. [CrossRef]

9. Culham, J.C.; Gallivan, J.; Cavina-Pratesi, C.; Quinlan, D.J. fMRI investigations of reaching and ego space in human superior parieto-occipital cortex. In Embodiment, Ego-Space and Action; Klatzky, R., McWhinney, B., Behrmann, M., Eds.; Press Taylor \& Francis: New York, NY, USA, 2008; pp. 247-274.

10. Cavina-Pratesi, C.; Monaco, S.; Fattori, P.; Galletti, C.; McAdam, T.D.; Quinlan, D.J.; Goodale, M.A.; Culham, J.C. Functional magnetic resonance imaging reveals the neural substrates of arm transport and grip formation in reach-to-grasp actions in humans. J. Neurosci. 2010, 30, 10306-10323. [CrossRef]

11. Vesia, M.; Bolton, D.A.; Mochizuki, G.; Staines, W.R. Human parietal and primary motor cortical interactions are selectively modulated during the transport and grip formation of goal-directed hand actions. Neuropsychologia 2013, 51, 410-417. [CrossRef]

12. Vesia, M.; Barnett-Cowan, M.; Elahi, B.; Jegatheeswaran, G.; Isayama, R.; Neva, J.L.; Davare, M.; Staines, W.R.; Culham, J.C.; Chen, R. Human dorsomedial parieto-motor circuit specifies grasp during the planning of goal-directed hand actions. Cortex 2017, 92, 175-186. [CrossRef] [PubMed]

13. Koch, G.; Del Olmo, M.F.; Cheeran, B.; Ruge, D.; Schippling, S.; Caltagirone, C.; Rothwell, J.C. Focal stimulation of the posterior parietal cortex increases the excitability of the ipsilateral motor cortex. J. Neurosci. 2007, 27, 6815-6822. [CrossRef] [PubMed]

14. Koch, G.; Del Olmo, M.F.; Cheeran, B.; Ruge, D.; Schippling, S.; Caltagirone, C.; Rothwell, J.C. Functional interplay between posterior parietal and ipsilateral motor cortex revealed by twin-coil transcranial magnetic stimulation during reach planning toward contralateral space. J. Neurosci. 2008, 28, 5944-5953. [CrossRef] [PubMed]

15. Koch, G.; Cercignani, M.; Pecchioli, C.; Versace, V.; Oliveri, M.; Caltagirone, C.; Rothwell, J.; Bozzali, M. In vivo definition of parieto-motor connections involved in planning of grasping movements. Neuroimage 2010, 51, 300-312. [CrossRef]

16. Davare, M.; Rothwell, J.C.; Lemon, R.N. Causal Connectivity between the Human Anterior Intraparietal Area and Premotor Cortex during Grasp. Curr. Biol. 2010, 20, 176-181. [CrossRef]

17. Hadjidimitrakis, K.; Bertozzi, F.; Breveglieri, R.; Bosco, A.; Galletti, C.; Fattori, P. Common neural substrate for processing depth and direction signals for reaching in the monkey medial posterior parietal cortex. Cereb. Cortex 2014, 24, 1645-1657. [CrossRef]

18. Bosco, A.; Breveglieri, R.; Chinellato, E.; Galletti, C.; Fattori, P. Reaching activity in the medial posterior parietal cortex of monkeys is modulated by visual feedback. J. Neurosci. 2010, 30, 14773-14785. [CrossRef]

19. Fattori, P.; Breveglieri, R.; Marzocchi, N.; Filippini, D.; Bosco, A.; Galletti, C. Hand orientation during reach-to-grasp movements modulates neuronal activity in the medial posterior parietal area V6A. J. Neurosci. 2009, 29, 1928-1936. [CrossRef]

20. Breveglieri, R.; Bosco, A.; Galletti, C.; Passarelli, L.; Fattori, P. Neural activity in the medial parietal area V6A while grasping with or without visual feedback. Sci. Rep. 2016, 6, 28893. [CrossRef] [PubMed]

21. Breveglieri, R.; de Vitis, M.; Bosco, A.; Galletti, C.; Fattori, P. Interplay between Grip and Vision in the Monkey Medial Parietal Lobe. Cereb. Cortex 2018, 28, 2028-2042. [CrossRef] [PubMed]

22. Fattori, P.; Raos, V.; Breveglieri, R.; Bosco, A.; Marzocchi, N.; Galletti, C. The dorsomedial pathway is not just for reaching: Grasping neurons in the medial parieto-occipital cortex of the macaque monkey. J. Neurosci. 2010, 30, 342-349. [CrossRef] [PubMed]

23. Gamberini, M.; Passarelli, L.; Fattori, P.; Zucchelli, M.; Bakola, S.; Luppino, G.; Galletti, C. Cortical connections of the visuomotor parietooccipital area V6Ad of the macaque monkey. J. Comp. Neurol. 2009, 513, 622-642. [CrossRef]

24. Passarelli, L.; Rosa, M.G.; Gamberini, M.; Bakola, S.; Burman, K.J.; Fattori, P.; Galletti, C. Cortical Connections of Area V6Av in the Macaque: A Visual-Input Node to the Eye/Hand Coordination System. J. Neurosci. 2011, 31, 1790-1801. [CrossRef] [PubMed]

25. Passarelli, L.; Rosa, M.G.; Bakola, S.; Gamberini, M.; Worthy, K.H.; Fattori, P.; Galletti, C. Uniformity and diversity of cortical projections to precuneate areas in the macaque monkey: What defines area PGm? Cereb. Cortex 2018, 28, 1700-1717. [CrossRef]

26. Galletti, C.; Fattori, P. The dorsal visual stream revisited: Stable circuits or dynamic pathways? Cortex 2018, 98, 203-217. [CrossRef]

27. Passarelli, L.; Gamberini, M.; Fattori, P. The superior parietal lobule of primates: A sensory-motor hub for interaction with the environment. J. Integr. Neurosci. 2021, 20, 157-171. [CrossRef] [PubMed]

28. Pitzalis, S.; Fattori, P.; Galletti, C. The human cortical areas V6 and V6A. Vis. Neurosci. 2015, 32, E007. [CrossRef] [PubMed]

29. Makris, N.; Kennedy, D.N.; McInerney, S.; Sorensen, A.G.; Wang, R.; Caviness, V.S., Jr.; Pandya, D.N. Segmentation of subcomponents within the superior longitudinal fascicle in humans: A quantitative, in vivo, DT-MRI study. Cereb. Cortex 2005, 15, 854-869. [CrossRef] [PubMed]

30. Parlatini, V.; Radua, J.; Dell'Acqua, F.; Leslie, A.; Simmons, A.; Murphy, D.G.; Catani, M.; de Schotten, M.T. Functional segregation and integration within fronto-parietal networks. Neuroimage 2017, 146, 367-375. [CrossRef] [PubMed] 
31. Li, J.Y.; Espay, A.J.; Gunraj, C.A.; Pal, P.K.; Cunic, D.I.; Lang, A.E.; Chen, R. Interhemispheric and ipsilateral connections in Parkinson's disease: Relation to mirror movements. Mov. Disord. 2007, 22, 813-821. [CrossRef] [PubMed]

32. Sattler, V.; Dickler, M.; Michaud, M.; Meunier, S.; Simonetta-Moreau, M. Does abnormal interhemispheric inhibition play a role in mirror dystonia? Mov. Disord. 2014, 29, 787-796. [CrossRef] [PubMed]

33. Chiappini, E.; Borgomaneri, S.; Marangon, M.; Turrini, S.; Romei, V.; Avenanti, A. Driving associative plasticity in premotor-motor connections through a novel paired associative stimulation based on long-latency cortico-cortical interactions. Brain Stimul. 2020, 13, 1461-1463. [CrossRef] [PubMed]

34. Cattaneo, L.; Barchiesi, G. Transcranial magnetic mapping of the short-latency modulations of corticospinal activity from the ipsilateral hemisphere during rest. Front. Neural Circuits 2011, 5, 14. [CrossRef] [PubMed]

35. Civardi, C.; Cantello, R.; Asselman, P.; Rothwell, J.C. Transcranial magnetic stimulation can be used to test connections to primary motor areas from frontal and medial cortex in humans. Neuroimage 2001, 14, 1444-1453. [CrossRef]

36. di Lazzaro, V.V.; Oliviero, A.; Profice, P.; Insola, A.; Mazzone, P.; Tonali, P.; Rothwell, J.C. Direct demonstration of interhemispheric inhibition of the human motor cortex produced by transcranial magnetic stimulation. Exp. Brain Res. 1999, 124, 520-524. [CrossRef]

37. Ferbert, A.; Priori, A.; Rothwell, J.C.; Day, B.L.; Colebatch, J.G.; Marsden, C.D. Interhemispheric inhibition of the human motor cortex. J. Physiol. 1992, 453, 525-546. [CrossRef]

38. Rothwell, J.C. Using transcranial magnetic stimulation methods to probe connectivity between motor areas of the brain. Hum. Mov. Sci. 2011, 30, 906-915. [CrossRef] [PubMed]

39. Fiori, F.; Chiappini, E.; Candidi, M.; Romei, V.; Borgomaneri, S.; Avenanti, A. Long-latency interhemispheric interactions between motor-related areas and the primary motor cortex: A dual site TMS study. Sci. Rep. 2017, 7, 14936. [CrossRef] [PubMed]

40. Fiori, F.; Chiappini, E.; Soriano, M.; Paracampo, R.; Romei, V.; Borgomaneri, S.; Avenanti, A. Long-latency modulation of motor cortex excitability by ipsilateral posterior inferior frontal gyrus and pre-supplementary motor area. Sci. Rep. 2016, 6, 38396. [CrossRef]

41. Karabanov, A.N.; Chao, C.C.; Paine, R.; Hallett, M. Mapping different intra-hemispheric parietal-motor networks using twin coil TMS. Brain Stimul. 2013, 6, 384-389. [CrossRef] [PubMed]

42. Cattaneo, L.; Giampiccolo, D.; Meneghelli, P.; Tramontano, V.; Sala, F. Cortico-cortical connectivity between the superior and inferior parietal lobules and the motor cortex assessed by intraoperative dual cortical stimulation. Brain Stimul. 2020, 13, 819-831. [CrossRef]

43. Ziluk, A.; Premji, A.; Nelson, A.J. Functional connectivity from area 5 to primary motor cortex via paired-pulse transcranial magnetic stimulation. Neurosci. Lett. 2010, 484, 81-85. [CrossRef] [PubMed]

44. Faul, F.; Erdfelder, E.; Lang, A.; Buchner, A. G*Power 3: A flexible statistical power analysis program for the social, behavioral, and biomedical sciences. Behav. Res. Methods 2007, 39, 175-191. [CrossRef] [PubMed]

45. Briggs, G.G.; Nebes, R.D. Patterns of Hand Preference in a Student Population. Cortex 1975, 11, 230-238. [CrossRef]

46. Avenanti, A.; Paracampo, R.; Annella, L.; Tidoni, E.; Aglioti, S.M. Boosting and decreasing action prediction abilities through excitatory and inhibitory tDCS of inferior frontal cortex. Cereb. Cortex 2018, 28, 1282-1296. [CrossRef]

47. Paracampo, R.; Pirruccio, M.; Costa, M.; Borgomaneri, S.; Avenanti, A. Visual, sensorimotor and cognitive routes to understanding others' enjoyment: An individual differences rTMS approach to empathic accuracy. Neuropsychologia 2018, 116, 86-98. [CrossRef]

48. Carducci, F.; Brusco, R. Accuracy of an individualized MR-based head model for navigated brain stimulation. Psychiatry Res. Neuroimaging 2012, 203, 105-108. [CrossRef] [PubMed]

49. Talairach, J.; Tournoux, P. Co-Planar Stereotaxic Atlas of the Human Brain: 3-Dimensional Proportional System: An Approach to Cerebral Imaging; Thieme Medical Publishers: Stuttgart, Germany; New York, NY, USA, 1988.

50. Ciavarro, M.; Ambrosini, E.; Tosoni, A.; Committeri, G.; Fattori, P.; Galletti, C. rTMS of Medial Parieto-occipital Cortex Interferes with Attentional Reorienting during Attention and Reaching Tasks. J. Cogn. Neurosci. 2013, 25, 1453-1462. [CrossRef]

51. Breveglieri, R.; Bosco, A.; Borgomaneri, S.; Tessari, A.; Galletti, C.; Avenanti, A.; Fattori, P. Transcranial Magnetic Stimulation Over the Human Medial Posterior Parietal Cortex Disrupts Depth Encoding During Reach Planning. Cereb. Cortex 2021, 31, 267-280. [CrossRef] [PubMed]

52. Vesia, M.; Prime, S.L.; Yan, X.; Sergio, L.E.; Crawford, J.D. Specificity of human parietal saccade and reach regions during transcranial magnetic stimulation. J. Neurosci. 2010, 30, 13053-13065. [CrossRef]

53. Gallivan, J.P.; McLean, A.; Culham, J.C. Neuroimaging reveals enhanced activation in a reach-selective brain area for objects located within participants' typical hand workspaces. Neuropsychologia 2011, 49, 3710-3721. [CrossRef] [PubMed]

54. Pitzalis, S.; Sereno, M.I.; Committeri, G.; Fattori, P.; Galati, G.; Tosoni, A.; Galletti, C. The human homologue of macaque area V6A. Neuroimage 2013, 82, 517-530. [CrossRef]

55. Rossi, S.; Hallett, M.; Rossini, P.M.; Pascual-Leone, A.; Safety of TMS Consensus Group. Safety, ethical considerations, and application guidelines for the use of transcranial magnetic stimulation in clinical practice and research. Clin. Neurophysiol. 2009, 120, 2008-2039. [CrossRef]

56. Rossini, P.M.; Burke, D.; Chen, R.; Cohen, L.G.; Daskalakis, Z.; di Iorio, R.; di Lazzaro, V.; Ferreri, F.; Fitzgerald, P.B.; George, M.S.; et al. Non-invasive electrical and magnetic stimulation of the brain, spinal cord, roots and peripheral nerves: Basic principles and procedures for routine clinical and research application. An updated report from an I.F.C.N. Committee. Clin. Neurophysiol. 2015, 126, 1071-1107. [CrossRef] [PubMed] 
57. Cardellicchio, P.; Dolfini, E.; Fadiga, L.; D'Ausilio, A. Parallel fast and slow motor inhibition processes in Joint Action coordination. Cortex 2020, 133, 346-357. [CrossRef] [PubMed]

58. Tomassini, V.; Jbabdi, S.; Klein, J.C.; Behrens, T.E.J.; Pozzilli, C.; Matthews, P.M.; Rushworth, M.F.S.; Johansen-Berg, H. Diffusionweighted imaging tractography-based parcellation of the human lateral premotor cortex identifies dorsal and ventral subregions with anatomical and functional specializations. J. Neurosci. 2007, 27, 10259-10269. [CrossRef] [PubMed]

59. Strick, P.L.; Kim, C.C. Input to primate motor cortex from posterior parietal cortex (area 5). I. Demonstration by retrograde transport. Brain Res. 1978, 157, 325-330. [CrossRef]

60. Zarzecki, P.; Strick, P.L. Input to primate motor cortex from posterior parietal cortex (area 5). II. Identification by antidromic activation. Brain Res. 1978, 157, 331-335. [CrossRef]

61. Bruni, S.; Gerbella, M.; Bonini, L.; Borra, E.; Coudé, G.; Ferrari, P.F.; Fogassi, L.; Maranesi, M.; Rodà, F.; Simone, L.; et al. Cortical and subcortical connections of parietal and premotor nodes of the monkey hand mirror neuron network. Brain Struct. Funct. 2018, 223, 1713-1729. [CrossRef] [PubMed]

62. Rathelot, J.A.; Dum, R.P.; Strick, P.L. Posterior parietal cortex contains a command apparatus for hand movements. Proc. Natl. Acad. Sci. USA 2017, 114, 4255-4260. [CrossRef]

63. Deng, Z.; Lisanby, S.; Peterchev, A. Electric field depth-focality tradeoff in transcranial magnetic stimulation: Simulation comparison of 50 coil designs. Brain Stimul. 2013, 6, 1-13. [CrossRef] [PubMed]

64. Scheperjans, F.; Eickhoff, S.B.; Hömke, L.; Mohlberg, H.; Hermann, K.; Amunts, K.; Zilles, K. Probabilistic maps, morphometry, and variability of cytoarchitectonic areas in the human superior parietal cortex. Cereb. Cortex 2008, 18, 2141-2157. [CrossRef] [PubMed]

65. Karabanov, A.; Jin, S.H.; Joutsen, A.; Poston, B.; Aizen, J.; Ellenstein, A.; Hallett, M. Timing-dependent modulation of the posterior parietal cortex-primary motor cortex pathway by sensorimotor training. J. Neurophysiol. 2012, 107, 3190-3199. [CrossRef] 